\title{
El mundillo del libro en la capital de Nueva España. Cajones, puestos y venta callejera (siglo XVIII)
}

\author{
Olivia Moreno Gamboa ${ }^{1}$ \\ UNAM-Instituto de Investigaciones Filológicas
}

La finalidad de este trabajo es mostrar la relevancia de las pequeñas librerías en el comercio librero de la ciudad de México. Fuentes inéditas de primera mano permiten apuntar la proliferación de estos modestos negocios en la segunda mitad del siglo XVIII y, asimismo, destacar la existencia de un nutrido grupo de vendedores ambulantes de impresos. Ambos fenómenos se sitúan en un momento de expansión del comercio atlántico del libro y de la producción tipográfica novohispana. También se muestra la estrecha relación que existía entre el estatus de las librerías y su localización urbana, de suerte que los cajones de libros de la Plaza Mayor y los puestos semi-callejeros situados en sus alrededores, se distinguieron por comercializar ediciones "populares», menudencias y volúmenes de segunda mano.

Palabras Clave: librerías; cajones de libros; puestos de libros; venta ambulante de libros; Ciudad de México; Nueva España; siglo XVIII.

Cómo citar este artículo / Citation: Moreno Gamboa, Olivia, "El mundillo del libro en la capital de Nueva España. Cajones, puestos y venta callejera (siglo XVIII)", Revista de Indias, LXXVII/270 (Madrid, 2017): 493-520, doi:10.3989/revindias.2017.016.

El interés de los historiadores por el estudio de las librerías novohispanas es bastante reciente. En particular, éstas han sido objeto de tesis de posgrado que se apoyan primordialmente en inventarios post-mortem levantados por orden del Juzgado de Bienes Difuntos, y en memorias de libros elaboradas por los libreros en respuesta a los mandatos de la Inquisición ${ }^{2}$. En menor medida se ha recurrido a los protocolos notariales de la ciudad de México, debido a que la falta de índices para el período colonial dificulta enormemente su consulta. Además de un par de estudios monográficos, contamos con

\footnotetext{
1 oli_moreno@hotmail.com ORCID iD: http//orcid.org/0000-0002-0836-7179.

2 Moreno Gamboa, 2009a. Suárez Rivera, 2009.
} 
varios artículos muy sugerentes sobre la oferta editorial de algunos impresores-mercaderes de libros y libreros ${ }^{3}$. Amén de su carácter novedoso -claro está, para la historiografía mexicana- el tema resulta atractivo por las múltiples posibilidades que ofrece para aproximarse al negocio editorial, en tanto que libreros y librerías jugaron un papel primordial en la circulación de los productos tipográficos. De manera complementaria, el estudio de una librería favorece la reconstrucción de la oferta cultural, de los autores y las obras que demandaba la sociedad, así como de las variadas formas que adoptaban los impresos para llegar a manos de los lectores.

En un primer acercamiento al tema realizado hace algunos años, ofrecí un estatus de la «comunidad» de libreros de la capital virreinal entre 1700 y $1778^{4}$. Por principio, señalé que existía una correlación entre la localización urbana de las tiendas y su importancia comercial, y que en el curso del siglo las grandes librerías tendieron a ubicarse al suroeste de la Plaza Mayor, zona habitada por los sectores más acaudalados. En segundo lugar, se mostró que hubo un aumento significativo del número de librerías y puntos de venta, que de 19 en la primera mitad del setecientos se elevaron a 45 en los años que van de 1751 a 1778. Ello se tradujo a su vez en un crecimiento de la «población» de libreros y tratantes de libros; la nómina ascendía entonces a 68 individuos, de los cuales 43 se mencionaban por primera vez en los documentos inquisitoriales correspondientes a la segunda mitad de la centuria. Apuntada la expansión del negocio de librería en el setecientos, me propuse establecer las principales -o más visibles- tipologías de comerciantes, advirtiendo al lector que la lista no era definitiva, en virtud de la rica información que aún guardaban las fuentes para seguir profundizando en el tema.

Con estas páginas se busca precisamente enriquecer nuestro conocimiento sobre los libreros y las librerías de la ciudad de México, y subrayar que su multiplicación en la segunda mitad del siglo XVIII se debió en buena medida al aumento de tratantes, espacios y modalidades de venta que suelen considerarse «menores»: cajones, cajoncillos, alacenas y demás puestos, así como vendedores de libros «a la mano». Si bien es válido aplicar a estos comercios el calificativo de «menores» porque, en efecto, su volumen de oferta era reducido en comparación con el de las librerías «gruesas», aquéllos también eran parte integral del sistema de venta urbano del impreso. Un sistema en el que participaban impresores-mercaderes de libros, propietarios y administradores de librerías, «cargadores» peninsulares de la Carrera de Indias y «almaceneros» o comerciantes mayoristas de la capital novohispana.

\footnotetext{
3 Megged, 1999. González y Gutiérrez, 2002. Moreno Gamboa, 2007. Montiel, 2015.

4 Moreno Gamboa, 2009b: 121-146.
} 
Las fuentes consultadas en los ramos Inquisición del Archivo General de la Nación y Ayuntamiento del Archivo Histórico del Distrito Federal dan indicios de una creciente presencia del libro en las calles; la venta callejera parece aumentar sin aparente control. La multiplicación de las librerías no confinó la venta de impresos a las tiendas especializadas. Incluso es posible que fueran los propios libreros establecidos quienes alentaran un comercio «informal» dentro y fuera de la ciudad. Debido a esto resulta más fructífero preguntarse -como ha hecho Jean François Botrel en sus trabajos sobre la librería española- qué función desempeñaron los puntos de venta menores en el conjunto del comercio librero y, más allá del negocio, cuál fue su importancia en la difusión del impreso entre distintos grupos de la población capitalina.

De ahí que en estas páginas la localización urbana y las características físicas de las librerías ocupen un lugar relevante. Esta información, aunada a la que proporcionan los documentos sobre la oferta tipográfica de las tiendas, dan al estudio del comercio librero su dimensión sociocultural, pues permiten captar la presencia del impreso en espacios concretos, vinculados a grupos particulares de la sociedad con demandas más o menos específicas de lectura.

\section{Los Caxones de libros del Parián y el Portal de Mercaderes}

El cajón era un tipo de establecimiento comercial de pequeñas dimensiones. Originalmente fueron de madera, luego se construyeron también de «cal y canto». Entre 1717 y 1802 los papeles de la Inquisición de México dan cuenta de 19 «cajones de libros», es decir, de tiendas especializadas en la venta de productos tipográficos. Es posible que en algunos cajones de ropa y mercería se ofertaran impresos; pero todo parece indicar que esos 19 cajones eran solo librerías.

La mayoría se concentraron en el Parián -mercado situado en la Plaza Mayor ${ }^{5}$ y el contiguo Portal de Mercaderes (ver mapa anexo al final). El primero se destinó a la venta de artículos importados de Asia y Europa: sedas, encajes, ropa, sombreros, zapatos, loza, muebles, joyas, relojes y otros objetos de consumo suntuario, entre los que también se contaban libros.

En el Portal de Mercaderes se vendían principalmente manufacturas y artesanías «de la tierra» o locales como ropa, mercería, alhajas, utensilios de

5 No debe perderse de vista, como señaló Robert Ricard, que la Plaza Mayor de la ciudad de México permitía una mayor circulación por estar abierta, a diferencia de algunas plazas españolas, como la de Madrid, que eran cerradas, Ricard, 1950: 325. 
barro... Pero eran sobre todo los juguetes y las flores de papel de colores lo que más llamaba la atención de cronistas y viajeros. Se trataba quizá del pasaje comercial más concurrido de la ciudad, donde además de comprar se iba a curiosear. Los más paseaban a pie, pero había quien se internaba en el Portal montando a caballo o en coche.

En tanto puntos estratégicos del comercio urbano y espacios de rica interacción social, el Parián y el Portal de Mercaderes fueron lugares privilegiados para la venta de impresos al menudeo. Pero ¿de qué tipo de librerías estamos hablando? ¿Qué clase de obras ofrecían a los lectores? ¿En qué se diferenciaban de las grandes librerías que abrieron en calles como San Agustín o la Monterilla al suroeste de la Plaza?

\section{TABLA 1. LIBREROS EN CAJONES (PROPIETARIOS Y ADMINISTRADORES) $1717-1802$}

\begin{tabular}{lll}
\hline \multicolumn{1}{c}{ Años } & \multicolumn{1}{c}{ Nombre } & \multicolumn{1}{c}{ Ubicación } \\
\hline 1717 & Pérez del Castillo, Agustín & Portal de Mercaderes \\
1745 & Andrade, Antonio & Parián \\
1745 & Blanca, Agustín de la & Parián \\
1745 & Estrada, Juan Antonio & Parián \\
1745 & Galisteo, José & Parián \\
1745 & Urtueta, Domingo & Parián \\
$1745-1757$ & Benavides, José Joaquín & Parián \\
$1757-1764$ & Cristóbal Zúñiga y Ontiveros & Parián \\
$1749 / 1766-68$ & Miguel Cueto & Portal / Parián \\
$1757-1773$ & Chaves, Juan Bautista & Parián \\
1757 & Navarro, José & Parián \\
1757,1764 & Paz y Zuleta, José Antonio & Parián \\
1757,1764 & Río, José del & Portal de Mercaderes \\
1764,1767 & Rioja, Antonio José de & Portal de Mercaderes \\
$1764-1786$ & Villegas Sandoval, Ignacio & Portal de Mercaderes \\
1802 & Paredes, José & Portal de Mercaderes \\
1802 & Azcárate, Rafael José & Parián \\
1802 & Calderón, Manuel Antonio & Parián \\
1802 & Hoz, José Antonio & Parián
\end{tabular}

Los cajones del Parián medían aproximadamente dieciséis 16 metros cuadrados y es de creerse que los del Portal tuvieran dimensiones similares. 
Tiendas tan reducidas como estas no podían alojar grandes cantidades de libros. De modo que se trataba de librerías pequeñas que acaso disponían de uno o dos ejemplares de una misma obra y en las que, por el contrario, solían abundar las «menudencias».

A mediados del siglo, en un cajón del Parián ubicado en el «arquillo»o puerta que salía al Real Palacio, se estableció Cristóbal de Zúñiga y Ontiveros (hermano del impresor Felipe). Manuel Suárez, quien ha estudiado el negocio de esta familia, mostró que en 1758 Cristóbal disponía de 2.032 títulos y unas existencias de 6.065 ejemplares. Poco más del $80 \%$ eran libritos y cuadernillos (en formatos octavo y dieciseisavo). De ellos tenía numerosas copias, pero si de volúmenes grandes se trataba, su oferta de reducía a un ejemplar. Así, pues, el grueso de su librería consistía en impresos menores, productos tipográficos ideales para almacenar en un cajón del Parián, como bien apunta Suárez ${ }^{6}$.

Si bien en la librería de Zúñiga y Ontiveros se hallaban obras de diversas materias, prevalecía la oferta de escritos religiosos de amplio consumo, uso reiterado y venta segura: rezos para la liturgia, sermones, vidas de santos, manuales de espiritualidad y devocionarios en sus diversas modalidades (novenas, septenarios, triduos). De hecho, los devocionarios representaban la mitad de su repertorio: 3.390 ejemplares de 451 títulos distintos 7.

Sin embargo lo anterior no significa necesariamente que la escasa disponibilidad de espacio condicionara por sí sola la oferta de las modestas librerías. Más bien cabría pensar que los libreros eligieron el establecimiento que mejor se adaptaba a sus posibilidades económicas. Ninguna legislación los obligaba a situarse en zonas y puntos específicos de la ciudad, como sí lo estuvieron, por ejemplo, los dueños de tiendas de pulperías hasta $1785^{8}$. La elección del lugar, del tipo de local y de los impresos a tratar debió responder sobre todo al nivel de riqueza del comerciante y a su capacidad para acceder a las distintas fuentes de crédito, indispensables para abastecerse de ese género de productos.

En cuanto al estatus de los dueños de estos cajones, las fuentes consultadas aportan escasa información. Por ello desconozco aún su origen geográfico y si el grupo se conformó exclusivamente por «españoles», es decir, por peninsulares y criollos. Aparte de Cristóbal Zúñiga y Ontiveros, sólo dispon-

6 Suárez Rivera, 2009: 41-46.

7 Ibidem: 88-89.

8 Una ordenanza de 1750 limitó la ubicación de las pulperías -tiendas misceláneas de artículos de consumo básico- a las esquinas de las calles. Para 1785 una real orden autorizó a los pulperos establecerse donde quisieran, en calles y plazas sin número ni demarcación fija. González Cruz, 2013: 23-24. 
go de algunos datos sobre la calidad social de dos libreros 9 . Ignacio Villegas Sandoval, con tienda en el Portal de Mercaderes, era en 1779 sargento primero «de una de las compañías urbanas» de la ciudad de México. A este título sumaba el cargo de capitán de comisarios de la Real Sala del Crimen de la Audiencia ${ }^{10}$. Como capitán su función era la de aprehender a ladrones, homicidas, fabricantes y vendedores de bebidas prohibidas y demás delincuentes que hallaran en la ciudad y «sus cinco leguas circulares». Su cargo, por el que recibía un sueldo de 500 pesos al año, le daba derecho a portar armas permitidas y a usar como distintivo un bastón con empuñadura de plata ${ }^{11}$. Sandoval era a un tiempo tratante de libros, subalterno de la milicia y una suerte de «jefe de policía». La venta de impresos era una más de sus actividades cotidianas, como debió serlo también para otros libreros. Por lo demás, es bien sabido que entre los comerciantes el desempeño de varias actividades -remuneradas y honoríficas- fue algo común.

Por su parte, José Antonio de la Hoz, dueño de un cajón de libros en el Baratillo grande del Parián, era terciario de la orden de la Merced en $1809^{12}$. Como se sabe, las órdenes terceras eran congregaciones de laicos estrechamente ligadas al clero regular. Buscaban imitar la vida austera y caritativa de los religiosos, promover la devoción y prepararse para una buena muerte. Para el común de la gente - dice Antonio Rubial- «un miembro de una orden tercera era un híbrido de seglar y religioso» ${ }^{13}$. Estos dos casos bastan por ahora para señalar que en el negocio de la librería novohispana se daban cita personajes con actividades e intereses diversos.

Cabe llamar la atención sobre la ausencia de apellidos extranjeros entre estos modestos tratantes. En cambio, entre los grandes libreros encontramos al menos a uno establecido: Agustín Dherbé o Dhervé, de ascendencia flamenca, quien tenía su tienda en la calle de Don Juan Manuel a mediados del siglo, una suerte de filial de la librería que su padre, Jacobo Dhervé, poseía en Sevilla ${ }^{14}$. La reventa de impresos a nivel urbano estaba, pues, mayoritaria-

9 Ontiveros era criollo, originario de Oaxtepec, hijo de Domingo de Zúñiga y Ontiveros y Nava y de María Teresa Montoya, asimismo nacidos en Nueva España. Suárez Rivera, 2009: 31 .

10 Archivo General de la Nación, México (AGN), Inquisición, vol. 1159, exp. 3.

11 AGN, Indiferente Virreinal, caja 5431, exp. 80, fechado el 28 de mayo de 1782, relativo al nombramiento de Vicente Elizalde como capitán de comisarios.

12 AGN, Inquisición, vol. 1310, exp. 8 y vol. 1445, exp. 16.

13 Rubial García, 2013: 62.

14 Con base en fuentes notariales Clara Palmiste demostró que los Dhervé eran de ascendencia flamenca, no francesa como supuso Amos Megged. Jacobo Dhervé era originario de Brujas y una vez establecido en Sevilla se desposó con Agustina Mónica de Oviedo, natural 
mente en manos de peninsulares y criollos; no así su distribución a escala intercontinental, negocio en el que la participación de libreros franceses, flamencos e italianos avecindados en España (algunos incluso naturalizados) era significativa ${ }^{15}$.

En cuanto a las prácticas de venta, las fuentes consultadas dejan entrever que a diferencia de los propietarios de almacenes de libros -entre quienes se cuentan impresores y algunos letrados que colaboraron con el Santo Oficio en las tareas de censura-, los dueños y administradores de cajones eran más propensos a quebrantar las normas que regían el comercio y circulación de libros. Ya fuera por desdén o porque, en efecto, desconocían los Índices y edictos emitidos por la Suprema Inquisición y el Santo Oficio de México, lo cierto es que los tratantes menores traspasaban con mayor facilidad la delgada línea que, a ojos de la Inquisición, separaba lo legal de lo prohibido.

En 1745, por ejemplo, el abogado Luis Mariano de Ibarra, dueño de una importante librería y a la sazón revisor y expurgador de libros del tribunal, denunció a Agustín de la Blanca, con cajón de libros en el Parián, por haber falsificado su firma y corregido «a su modo» varios Ramilletes de divinas flores ${ }^{16}$, Paraísos del alma cristiana y Ejercicios del arzobispo Juan de Palafox, libros de devoción muy buscados en aquel entonces. Ibarra se enteró de lo sucedido por un abogado amigo suyo, que le compró dichos títulos a De la Blanca.

Mientras llegaba la respuesta del tribunal, Ibarra se dio a la tarea de visitar los cajones del Parián y sus alrededores. Para su sorpresa halló numerosos Lunarios perpetuos, Cartillas morales, Estaciones del Calvario, Gritos del Purgatorio y otros títulos en las mismas condiciones. De inmediato informó a los inquisidores que estos y otros libros

...se andan vendiendo por las calles, en el Baratillo de esta ciudad, y en los portales, y los cajones de ellas, sin corrección alguna, y otras con ella, pero sin firma alguna de los revisores de aqueste Santo Tribunal, siendo así que muchos de los que se intitulan Misterios de la misa, están prohibidos in totum, siendo de la impresión de Flandes ${ }^{17}$.

de la ciudad hispalense. Palmiste, 2010: 260. Megged, 1999: 152, se equivoca también al afirmar que Agustín Dhervé fue "pionero en abrir una librería comercial en la Ciudad de México». A principios del siglo XVIII ya existían tiendas de libros en la capital novohispana, que operaban de manera independiente al negocio tipográfico.

$15 \mathrm{Al}$ respecto véase Moreno Gamboa, 2015. Gómez Álvarez, 2011.

16 Sobre la circulación y censura en Nueva España de este popular libro castellano de devoción ver Moreno Gamboa, 2016.

17 AGN, Inquisición, vol. 905, exp. 1. 
El tribunal ordenó entonces una visita formal al Parián y la requisa de todos los ejemplares que estuvieran sin expurgar o mal corregidos. De igual manera se confiscaron impresos a Domingo Urtueta, José Galisteo, Juan Antonio Estrada, Antonio Andrade y José Benavides, todos ellos mercaderes con cajones. Pero el informe de Ibarra indica que además de estos seis había otros cajones que vendían impresos (sin que podamos asegurar si se trataba exclusivamente de tiendas de libros): "habiendo pasado a otros cajones, y conociendo que se había de gastar mucho tiempo en ver y reconocer los libros que expresa dicho decreto, tuve por conveniente notificar a los cajoneros que los pasaran a este Sto. Oficio» ${ }^{18}$. Una vez corregidos, los ejemplares fueron devueltos a sus dueños, a quienes en adelante se autorizó expurgarlos bajo la obligación de acudir por la firma de un revisor.

De modo que en los cajones del Parián la venta de obras prohibidas y sin expurgar era moneda corriente. Los tratantes no contaban con los instrumentos indispensables (índices y edictos) tanto para conocer la normativa vigente sobre el comercio de libros, como aquellas lecturas sospechosas y prohibidas que, supuestamente, debían apartar y llevar al tribunal. Cuando en 1757 el Santo Oficio preguntó a todos los libreros de la ciudad si contaban con el Índice Expurgatorio más reciente (el de 1747), resultó que los únicos que carecían de él eran dos cajoneros: José Antonio Paz y Zuleta, en el Parián, y José del Río, en el Portal de Mercaderes ${ }^{19}$.

Por otra parte, la denuncia de Ibarra viene a corroborar lo que ya se dijo sobre el inventario de libros de Zúñiga y Ontiveros, esto es, que la oferta de los cajones consistía básicamente en libritos piadosos, cuadernillos de rezos, calendarios y pronósticos de temporales. Era, sí, un surtido limitado, pero un surtido que respondía estricta y eficazmente a necesidades «primarias» en materia del consumo del impreso, como bien apunta Botrel ${ }^{20}$. Por ello, los dueños de estas modestas librerías estuvieron provistos de numerosas copias: tan sólo a Agustín de la Blanca el Santo Oficio le requisó 29 Ramilletes, 117 Misterios, 260 Ejercicios de Palafox y 314 del Compendio de la tercera orden; es decir, 720 ejemplares de unos títulos muy populares ${ }^{21}$.

A mediados del siglo XVIII otro librero, Juan Bautista Reyes Chávez, situado al igual que Ontiveros en uno de los «arquillos» del Parián, tenía su cajón bien provisto de calendarios, llamados también lunarios o efemérides. Estos cuadernillos ofrecían el pronóstico del clima y explicaban fenómenos
18 Idem.
19 Ibidem, vol. 1048, exp. 2.
20 Botrel, 1988: 16.
21 AGN, Inquisición, vol. 905, exp. 1. 
astronómicos, como los eclipses y el paso de cometas. De ahí su utilidad para labradores, comerciantes, arrieros, marinos y médicos. Por lo común incluían un calendario anual de las fases lunares, las fiestas móviles y el santoral. En 1758 el matemático Miguel Francisco de Illarregui, autor de varios lunarios, envió a Chávez desde la ciudad de Puebla de los Ángeles (la segunda más importante del virreinato) nada más ni nada menos que 800 pronósticos y 1.000 calendarios $^{22}$. En esos años, Nueva España sólo contaba con talleres tipográficos en México y Puebla, lo cual sugiere que la remesa de lunarios era de factura angelopolitana y de la autoría del propio Illarregui. Así, Chávez hizo las veces de intermediario entre las prensas poblanas y los lectores de la capital virreinal. Además llama la atención la relación entre autor y librero. Aquí no se hace presente el impresor, siendo Illarregui quien abastece directamente a Chávez.

Como ya se dijo, también en el Portal de Mercaderes (propiedad del conde de Santiago de Calimaya) se abrieron librerías. A principios del setecientos Agustín Pérez del Castillo tuvo allí su modesto cajón, sobre el que trataré más adelante. En las décadas centrales del siglo, habiéndose ya reedificado el Portal al gusto de la época ${ }^{23}$, se establecieron Miguel Cueto, Antonio José de Rioja e Ignacio Villegas Sandoval, a quien se mencionó páginas atrás. Sandoval seguía activo en 1780, tal vez al frente del mismo cajón ${ }^{24}$. En 1802 la nómina de libreros levantada por la Inquisición de México sólo informó de una librería en el Portal, la de José Paredes ${ }^{25}$.

Cabe observar que desde mediados del siglo XVIII el Portal de Mercaderes comenzó a ganar importancia en el comercio urbano del impreso, quizás porque la reedificación del pasaje lo hizo más atractivo a ojos de los libreros.

22 Ibidem, vol. 976, exp. 19. José Toribio Medina sólo registra dos títulos de Illarregui, pero ambos publicados en la ciudad de México, no en Puebla: Pronóstico y Particular Diario calculado... para el año del Señor de 1751, y meridiano de la Puebla de los Ángeles; y Piscator poblano. Explicación de un eclypse de Sol que se verá el día 22 de Marzo de este presente año de 1755. Medina, 1989, vol. V.

23 Autos sobre la nueva fábrica de Portales, mandada hacer por S.E. cometida al Sor Oydor Toro, 1753, Archivo Histórico del Distrito Federal, México D.F. (AHDF), Portales, vol. 3692, exp. 1. Para 1753 sólo faltaba reconstruir el tramo de los portales que hacía esquina con la calle de San Francisco, y sobre el cual existían cinco casas propiedad del Mayorazgo de Álvaro de Figueroa, vecino de Jerez de la Frontera. El Ayuntamiento opinaba que gracias a esa obra arquitectónica (que modificó la fachada de los portales) se había «ilustrado y hermoseado esta Nobilísima Ciudad».

24 AGN, Inquisición, vol. 1191, exp. 1. En 1780 Villegas, «vecino de esta ciudad y comerciante en libros», solicitó licencia al Santo Oficio para proceder al avalúo de los libros que pertenecieron al marqués del Jaral del Berrio.

25 Ibidem, vol. 1409, exp. 1. 
Siendo así, no extraña que a raíz del saqueo del Parián -ocurrido durante el motín de la Acordada en 1828-, su consiguiente abandono y su demolición en 1843, más libreros buscaran acomodarse en Mercaderes y el contiguo Portal de Agustinos ${ }^{26}$. A fin de cuentas, tal desplazamiento venía dándose ya desde finales del período virreinal.

Por el momento sólo se ha recuperado el inventario de un cajón de libros del Portal de Mercaderes, que data de 1716. La oferta de Agustín Pérez del Castillo comprendía 502 títulos -pocos repetidos- y más de un centenar de comedias cuyo número de copias no se anotó. Se trataba de una librería diminuta con un surtido cuatro veces inferior al que ofrecería Ontiveros en los años sesenta ${ }^{27}$. Y es que en tiempos de Pérez del Castillo el negocio librero de la capital era muy reducido. Además, en las dos primeras décadas del siglo el comercio entre la Metrópoli y las colonias se contrajo a causa de la Guerra de Sucesión, conflicto que en buena medida se libró en los puertos y mares del Atlántico.

Entre los estudiosos del comercio de libros en la época moderna es un lugar común afirmar que no había una clara distinción entre la venta de libros «nuevos, viejos y usados» ${ }^{28}$. Sin embargo, el cotejo de varios inventarios de librerías menores de la ciudad de México del setecientos, permite advertir cierta especialización. Es el caso del cajón de Pérez del Castillo, donde se ofertaban ediciones de entre cincuenta y cien años de antigüedad. Los libros «nuevos»-es decir, publicados en años recientes a la elaboración del inventario- eran excepcionales. En vista de la edad de la librería no es raro que algunos volúmenes estuvieran maltratados, rotos o carecieran de portada; tampoco que hubiera ediciones incompletas, faltas de uno o varios tomos ${ }^{29}$. Ante estas evidencias sobre la antigüedad y el estado físico de los libros, es posible sugerir que la de Pérez del Castillo era una librería «de viejo».

Cabe aclarar que el término no era del todo inusual en la época; ya en 1706 lo encuentro citado por el nuncio de la Inquisición de México, a propósito de la orden emitida por el tribunal para que se requisaran los Ramilletes de divinas flores impresos en Madrid. El nuncio informó que halló porción de ejemplares justamente «en un cajón de la Plaza que es librería de viejo» ${ }^{30}$.

¿Cómo se proveía Pérez del Castillo de libros tan añejos? Es factible que los comprara a particulares, o bien que acudiera a las almonedas o remates

\footnotetext{
26 Guiot de la Garza, 2003: 437-510.

27 Actualmente estoy realizando el estudio de esta librería.

28 Hablo aquí de los libros como objetos materiales, no de los textos contenidos en ellos.

29 AGN, Inquisición, vol. 763, exp. 2.

30 Idem. El subrayado es mío.
} 
públicos de bibliotecas de difuntos ${ }^{31}$. De ahí que el inventario comprenda numerosos obras facultativas en latín, artes de gramática, manuales de sacramentos y sermones, textos indispensables para la formación y el desempeño profesional de los sacerdotes.

De lo anterior se desprende otra pregunta: ¿hasta qué punto las fuentes de abastecimiento accesibles a los libreros determinaban el tipo de oferta de sus tiendas? ¿En las librerías grandes predominaban las ediciones nuevas y en las menores las viejas y usadas? Fuese por uno u otro medio, lo cierto es que el negocio de Pérez del Castillo consistió en reciclar viejos volúmenes y revenderlos en el Portal de Mercaderes.

\section{CAXONCILlos, Mesillas y PUESTOS DE LiBROS}

Si los cajones de libros tendieron a concentrarse en el mercado del Parián y más tarde en el Portal de Mercaderes, por el contrario, los caxoncillos, alazenitas, mesillas y demás puestos (descritos en los documentos siempre en diminutivo) estaban dispersos en esquinas, portales, plazas y puentes (ver mapa anexo al final). Ello no significa que sus dueños decidieran libremente su ubicación; incluso estos humildes comercios estaban sujetos a controles y pagaban un alquiler mensual por su «hueco» o «paraje» al Ayuntamiento, o bien al propietario del inmueble que los cobijaba (por ejemplo, al convento de San Agustín en el caso del Portal que llevaba su nombre) ${ }^{32}$.

Vender en librerías semifijas debió ser una faena engorrosa. Se sabe que los dueños o encargados de caxones portátiles «los sacaban desde por la mañana, teniéndolos allí todo el día, y al acabar de la tarde los metían en las Bodegas, que para guardarlos alquilaban separadamente ${ }^{33}$. Aun tratándose de puestos de madera fijados en el suelo, o de alacenas empotradas en paredes y columnas, cabe suponer que los impresos se llevaban a mejor resguardo al final de cada jornada ${ }^{34}$.

31 Sobre las almonedas de libros véase el trabajo de Gómez Álvarez, 2006.

32 Juan A. Cervantes por el convento de San Agustín pide que los comerciantes de las calles de la Acequia o Tlapaleros, no impidan a las fruteras, situarse en el Portal de Agustinos, 1751, AHDF, Portales, vol. 3696, exp. 7. El convento era dueño del «Portal de los Mercaderes, que está en la calle de la Acequia, frente de los Tlapaleros».

33 Para el informe con los autos, que la Nma Ciudad sigue con el poseedor de el Mayorasgo que nombran de Guerrero en el Portal de las Flores sobre cajoncillos en la calle del Señor San José, 1780, AHDF, Portales, vol. 3696, exp. 12.

34 Los cajoncillos de madera estaban cubiertos por tejado o techo de tejamanil, sostenido por «cuartones» o vigas clavadas en el suelo. Véase la descripción en el expediente antes citado. 
En Madrid existía también un conjunto de pequeñas librerías en el corazón de la ciudad, en las escalinatas o «gradas» de la iglesia del convento agustino de San Felipe el Real. Gabriel Sánchez explica que estas modestas tiendas consistían en «casetas» de madera «con tejado a dos aguas» y en «puestos» de libros «contenidos en cajones de madera arrimados a la pared, a la manera de los tradicionales buquinistas del Sena». Durante el siglo XVIII no más de ocho libreros tuvieron puestos en las gradas; pero además de puesto algunos tuvieron «tienda abierta». El surtido típico de los puestos de San Felipe se componía de zarzuelas y comedias, calendarios y pronósticos, almanaques y devocionarios; esta oferta se complementaba con la venta de papeles de carácter polémico. Consistía, en suma, de «textos de circunstancias, inmediatos a los requerimientos de la actualidad y en cierto sentido de carácter más efímero ${ }^{35}$. Esta oferta se asemejaba mucho a la de los cajones y puestos de la Plaza Mayor de la ciudad de México.

Otro elemento que permite situar mejor estas modestas librerías en el conjunto del comercio urbano del impreso, son los montos de las rentas que pagaban por el derecho de piso. Mientras que por un cajón del Parián se cobraba entre 100 y 200 pesos anuales, por un cajoncito de madera fijo se pedían alrededor de 50 pesos. El precio disminuía a 2 pesos al mes (o 24 al año) si se trataba de «alacenitas», «mesitas» o «puestecitos» semifijos. Así, para poder pagar tan sólo el alquiler del puesto, un librero con «mesilla» debían vender al mes un volumen o una docena de catecismos ${ }^{36}$.

Además de esta consideración, cabe preguntarse qué significaba pagar dos, 50 o hasta 300 pesos por el alquiler de un espacio comercial. Un contador del Ayuntamiento, cuyo salario anual rozaba los 2.000 mil pesos, podía arrendar un cajón con cierta facilidad. Pero la renta de una alacena le habría significado a un peón la tercera parte de su salario, calculado en 6 pesos mensuales. Estos precios muestran la disparidad que existía entre los comerciantes de libros, lo que viene a reflejar la enorme desigualdad económica y social de la población capitalina.

Ubicamos a cuatro libreros al frente de este tipo de comercios, todos en la segunda mitad del siglo XVIII ${ }^{37}$. José de Ávila tuvo una «mesilla de libre-

35 Sánchez Espinosa, 2011: 147-151.

36 A mediados del siglo XVIII el precio promedio de un libro era de 1 peso 2 reales, Moreno Gamboa, 2009a: 91-93. Para precios de impresos a principios del XIX véase Gutiérrez Lorenzo, 2007: 120-122.

37 Existe un quinto, pero no he hallado referencias sobre su ubicación: Antonio Sevilla, dueño de un puesto, declaró al Santo Oficio que no entregó la memoria obligada por «no haber tenido trato de libros hasta ocho meses a esta parte». AGN, Inquisición, vol. 825, exp. 3. 
ría» «en la calle derecha de frente de la catedral entre los cajones de fierro» del Parián. Ávila vendía tanto libros «propios, como agenos [sic] y de encomienda ${ }^{38}$. La práctica de la consignación fue común a todos los comerciantes de libros, así grandes como pequeños. Es casi seguro que ningún librero fuera dueño en su totalidad de los impresos que vendía, y que parte de su mercancía estuviera sujeta a crédito o a comisión.

En el centro del Parián, en una plazuela a cielo abierto se vendían objetos viejos y usados en puestos y tenderetes: a este mercado de «segunda mano» se le conocía como el Baratillo grande o mayor ${ }^{39}$. Allí, precisamente, Sebastián Zumeta colocó su «mesilla de libros». Zumeta operaba más bien como consignatario, pues en 1768 declaró al comisario de la Inquisición que los impresos que vendía los sacaba «de otras librerías grandes». Por la misma época algunos puestos callejeros de Madrid eran sostenidos por dos o más libreros formales ${ }^{40}$. ¿Sería el caso de esta mesilla?

También en dicho año aparece Juan de León con «cajoncillo o mesilla» en la esquina del Portal de las Flores, situado a un costado de las casas del cabildo, frente a la Plaza Mayor. El comercio del Portal era principalmente de dulces, sarapes, rebozos, sombreros y otros productos locales. Cuatro años antes, en 1764, el Santo Oficio incluyó a León entre los vendedores de libros «a la mano». En 1768, interrogado sobre su procedencia, declaró que «hacía pocos días que tomó el cajón» ${ }^{41}$. Es posible entonces que León pasara de ser un librero ambulante a uno modestamente establecido. Dos años después seguía conservando este último estatus, ya que en 1771 presentó al tribunal una memoria de los libros, dando coordenadas precisas de la ubicación de su puesto: «Puente de las Mamoneras frente del Portal de las Flores». Este era uno de los puentes que permitía cruzar la Acequia Real, a la altura de la Plaza Mayor ${ }^{42}$. Contiguos al portal se encontraban la plaza y mercado de alimen-

38 Lo encuentro activo entre 1764 y 1771 en el mismo sitio. AGN, Inquisición, vol. 1048, exp. 2 y vol. 1172, exp. 14. Aún desconozco si José Ávila fuera pariente de Juan de Dios Ávila, quien en los mismos años administraba la imprenta y librería de la Bibliotheca Mexicana del canónigo Juan José de Eguiara y Eguren.

39 Existía además el Baratillo Menor, pero se ubicaba afuera del Parián, en la propia Plaza Mayor. Ya a finales del siglo XVII era famoso por ser un punto de venta de objetos robados, armas prohibidas y juegos de azar fraudulentos. En el siglo XIX el Baratillo Menor daría origen al célebre mercado de la Lagunilla, llamado así por situarse en la plaza del mismo nombre donde hoy continúa. Ramírez Maya, 2012: 136.

40 Agulló y Cobo, 1992.

41 AGN, Inquisición, vol. 825, exp. 3 y vol. 1172, exp. 14.

42 Para el informe con autos, que la Nma Ciudad sigue con el posedor de el Mayorasgo que nombran de Guerrero en el Portal de las Flores sobre cajoncillos en la calle del Señor San Joseph, 1780, AHDF, Portales, vol. 3696, exp. 12. El Puente de las Mamoneras medía 
tos del Volador y el edificio de la Universidad; por tanto debió ser un paraje muy transitado por estudiantes y catedráticos.

¿En qué consistía la oferta de este cajoncito? León declaró escasos 136 títulos: 24 volúmenes grandes o infolio, un centenar de libros medianos en cuarto y octavo, y trece «pequeñitos» de literatura piadosa ${ }^{43}$. Cabe hacer notar que entre los infolio había varias ediciones del siglo XVII, como unas Reglas de la orden de Santiago publicadas en Madrid en 1655, o las Obras espirituales de fray Luis de Granada impresas también en la Corte en 1677. En cambio, la mayoría de los impresos medianos eran del XVIII, lo cual corrobora el progresivo desuso del gran formato.

Importa subrayar la presencia en esta diminuta librería de 18 ediciones publicadas en la ciudad de México en el curso del setecientos, con excepción de la Estrella de el Norte Mexicano de Francisco de Florencia, que data de 1681 según el inventario ${ }^{44}$. Así, vemos que en este cajoncillo la venta de impresos de factura doméstica era relevante; éstos bien pudieron salir de las librerías de las propias imprentas y, por supuesto, de las almonedas de difuntos. Para un modesto librero debió ser mucho más fácil en términos económicos y operativos abastecerse de impresos de factura novohispana que de ediciones europeas.

En cuanto a las temáticas, un somero examen deja ver el predominio del libro religioso, sobre todo de vidas de santos y manuales para «el buen cristiano»; en realidad son escasos los textos de saberes profanos ${ }^{45}$. Entre los impresos pequeñitos se cuenta un par de oficios litúrgicos -uno de ellos publicado en Amberes en 1757-, siendo el resto de espiritualidad.

seis varas de ancho, que equivalen aproximadamente a cinco metros. En el expediente consultado se afirma que por este puente podía cruzar fácilmente un coche de caballos.

43 AGN, Inquisición, vol. 1100, exp. 6.

44 A continuación la lista de las ediciones mexicanas tal como se anotaron en el inventario, por lo cual se prescinde del uso de cursivas: Arte de Carochi (1759), Vida del padre Margil, de Isidro Celis de Espinosa (1737), Sermones en mexicano de fray Martín de León (1710), Zodiaco Mariano de Francisco de Florencia (1758), Mes de San Ignacio del padre Domingo Estanislao (1746), Sucesos morales de Oviedo (1754), Crisis de la Compañía de Jesús del padre Andrés (1725), Aurora alegre de fray Francisco Antonio de Vereo (1730), Año santificado de Ignacio Thomay (1755), Reducciones de Plata y Oro de Nicolás Berdugo (1752), El comulgador por el mismo (1714), Reglas de Santo Domingo por el Dr. Gabriel Berdugo [Berdú] (17??), Peregrinación christiana de fray Joaquín Osuna (17??), Vida christiana por Gerónimo Durati (1750), Filomena Mariana por fray Joaquín de Ortega (1760), la Virgen en el templo por el padre José Tercero (1723) y Místico relox (1750).

45 Como los Elementos de matemáticas de Ulloa (Madrid, 1706), Elementos geométricos de Euclides por Jacobo de Mora (1689), Compendio de contratos públicos de Melgarejo (1758) y las Reducciones de plata y oro de Nicolás Verdugo (México, 1752). 
Por último, resta mencionar a Juan Manuel Estarrona, dueño de una modesta pulpería llamada La Migaja, ubicada en el barrio de la Misericordia. A mediados de 1788 la traspasó en 622 pesos para dedicarse a la venta de impresos $^{46}$. Jorge Silva señala que al gremio de pulperos de la ciudad de México pertenecían sobre todo españoles, criollos y mestizos, pues a los miembros de las castas les estaba prohibido abrir o administrar ese tipo de tiendas. La mayoría de los tenderos eran personas pobres «que se dedicaban al comercio como una actividad más». Ello, sin embargo, no les impidió utilizar el «don» «como signo de prestigio y calidad social» ${ }^{47}$. Estarrona entra pues en el sector de comerciantes minoristas pobres de la capital.

Don Juan Manuel colocó su «puesto de libros» «en la plazuela del conde de Santiago» ${ }^{48}$, situada tres calles al sur de la Plaza Mayor. Alrededor de esa plazuela, llamada en realidad de Jesús, se levantaban las casas del conde de Santiago de Calimaya. Allí se formaba un mercado de «cajoncillos, tinglados, puestos portátiles y viento» que a finales del siglo XVIII administraba el Ayuntamiento ${ }^{49}$. Poco puedo decir sobre la oferta de este librero semi-ambulante, sólo que en 1795 vendió al guardián del convento de Calpulalpan (Tlaxcala) la Vida de Federico II, Rey de Prusia, una edición recién publicada en España ${ }^{50}$.

La actividad comercial de Estarrona y otros tratantes del virreinato confirma lo ya observado por François Lopez para la España borbónica: no hacía falta ser librero para vender libros ${ }^{51}$. Era una realidad común al mundo hispánico. El caso de Juan Manuel indica también que a fines del período colonial el comercio minorista de impresos se volvió un giro cada vez más atractivo y accesible para ciertos sectores socioeconómicos de la ciudad de México, como se verá a continuación.

46 Las pulperías eran tiendas de abarrotes o productos misceláneos de consumo básico. La Migaja se encontraba «en el paraje que llaman de Pila Seca, esquina de la calle de la Misericordia», en el extremo noroeste de la ciudad. De acuerdo con la escritura del traspaso, Estarrona recibió en 1789, 300 pesos al contado, 100 se le pagarían en mensualidades de 10 pesos, y los 222 restantes en el plazo de un año, AGN, Consulado, vol. 221, exp. 3.

47 En 1781 se empadronaron 221 pulperías en la ciudad: más del 50\% tenía una inversión menor a mil pesos y sólo 52 tiendas tenían un capital de 4.000 pesos en promedio. Para 1795 el número de pulperías descendió a 154; cabe la posibilidad de que «un grupo pulperos prósperos» absorbiera las tiendas de los más pobres, Silva Riquer, 2004: 296-302.

48 El Santo Oficio anotó que el puesto se ubicaba «en la plazuela del Conde de Santiago», AGN, Inquisición, vol. 1194, exp. 8.

49 AGN, Indiferente Virreinal, caja 692, exp. 2.

50 AGN, Inquisición, vol. 1194, exp. 8. El Catálogo Colectivo del Patrimonio Bibliográfico Español sólo registra una edición de esta obra correspondiente al siglo XVIII, publicada entre 1788-1789 en Madrid en la Imprenta Real, en 4 volúmenes, http://ccpb_opac.mcu.es/.

51 Lopez, 1984a: 174. 
VENDEDORES DE LIBROS «A LA MANO»

Las listas de libreros de la capital virreinal elaboradas por la Inquisición en la primera mitad del siglo XVIII, no registran a vendedores «a la mano». De ello no se desprende que la ciudad de México careciera de un comercio ambulante de impresos. A este respecto, los propios papeles del Santo Oficio ofrecen desde cortas menciones hasta denuncias sobre la venta callejera de libros prohibidos. Pero dos listas posteriores redactadas por el nuncio del tribunal, una de 1764 y otra de 1771, dan cuenta de un nutrido grupo de libreros ambulantes ${ }^{52}$. En el siguiente cuadro se reproducen sus nombres:

Tabla 2. Vendedores de libros «A LA MANO» EN la CIUDAD DE MÉXICO

\begin{tabular}{ll}
\hline \multicolumn{1}{c}{1764} & \multicolumn{1}{c}{1771} \\
\hline Ávila, José & Aguilera, José de \\
Castillo, Félix del & García, José \\
Cordero, Clemente & Llave, Santiago de la \\
Correa [y Nieto], Juan & Morrato, José \\
Cueto, José & Noriega, Lorenzo \\
Cueto, Miguel & Ochoa, José \\
Dávila Villagómez, José & Pérez de Senteno, Francisco \\
Díaz, José & Quinto, José \\
Fernández Posada, José & Rodríguez, Francisco \\
Haro, Tomás de & Sánchez, Bernardo Eduardo \\
Jiménez, Felipe & Sánchez, Joaquín de \\
León, Juan de & Sánchez, Juan de Dios \\
Maceda, Tomás de & \\
Morales, Juan José & \\
Morelos, José María & \\
Pérez Senteno, Francisco & \\
Rodríguez, Ignacio & \\
Sánchez, Bernardo & \\
Suárez, Miguel & \\
Taboada, Juan José de & \\
Zumeta, Sebastián &
\end{tabular}

52 AGN, Inquisición, vols. 1048, exp. 2 y vol. 1172, exp. 14. 
En 1764 se cuentan 21 tratantes, de los cuales la mitad seguía ejerciendo la misma modalidad de venta en 1767 o en 1768. De estos once, uno figura ya en este último año con «puesto de libros» en el Baratillo grande: Sebastián Zumeta, de quien se habló páginas atrás.

En el cuadro se observa que solo dos vendedores, Francisco Pérez Senteno y Bernardo Sánchez, aparecen también en la lista de 1771. Si bien el grupo se redujo a doce, considero que se trata, en las dos listas, de cifras relevantes que no alcanzan a reflejar la importancia de una práctica comercial que se sospecha iba en aumento. Ya en 1764 el nuncio del Santo Oficio (Andrés López Barba, encargado de levantar las nóminas) advertía a los inquisidores sobre la dificultad que tenía para «formar juicio» del número de estos tratantes, «por salir cada día distintos, pues cualquiera se introduce a vender libros a su arbitrio» ${ }^{53}$. Siete años después volvería a insistir sobre la imposibilidad de «hacer cómputo cierto» de ellos. Así, es posible que no disminuyeran, sino más bien que el abrumado nuncio renunciara a ubicarlos a todos.

Todo lleva a pensar que la ausencia de un gremio de libreros en la ciudad de México favoreciera la multiplicación de revendedores ocasionales, al no existir mecanismos legales para regular y limitar el comercio de impresos a un grupo homogéneo desde el punto de vista socio-económico. En la Metrópoli, por el contrario, estos gremios se formaron desde fechas tempranas en las ciudades donde la actividad tipográfica se encontraba más desarrollada (Zaragoza, Barcelona). En el caso de Madrid, su designación como capital del reino alentó el florecimiento de la imprenta y el comercio librero, lo que a su vez favoreció la organización de una corporación en 1611: la Hermandad de San Gerónimo de Mercaderes de libros. Al margen de sus actividades piadosas, su principal objetivo fue disputar el derecho a obtener lucrativos privilegios de imprenta. Una vez logrado, la Hermandad pudo dar salida a un importante repertorio de obras de amplísima demanda y, al mismo tiempo, ejercer un control directo sobre las librerías que pertenecían a sus cofrades. $\mathrm{Su}$ actividad editorial se prolongó hasta mediados del siglo XVIII, pero a partir de la década de 1760 comenzó a perder fuerza debido a las restricciones impuestas a los privilegios, y a una política regia contraria a la estructura gremial ${ }^{54}$. De ahí el impulso dado por la Corona a la Real Compañía de Impresores y Libreros del Reino, constituida a mediados de 1763 y a la cual se integraron los libreros más ricos de la Hermandad de San Gerónimo. Con esta empresa de accionistas se esperaba poder hacer frente a la competencia de los

\footnotetext{
53 Ibidem, vol. 1048, exp. 2.

54 Paredes Alonso, 1989: 23-37.
} 
editores extranjeros y recuperar la producción de los libros litúrgicos con el fin de reanimar a la deprimida industria tipográfica española ${ }^{55}$.

Con todo, estos poderosos gremios debieron convivir con una tropa de «copleros, retaceros» y con los ciegos de la poderosa Cofradía de Nuestra Señora de la Visitación. La Cofradía tuvo el derecho exclusivo de distribución, en la vía pública, de los «pliegos sueltos» que no excedieran de cuatro hojas: relaciones, comedias, gacetas, devocionarios, almanaques, guías de forasteros... En esquinas y afuera de las iglesias los ciegos recitaban en voz alta los «papeles», en ocasiones acompañándose de un instrumento musical ${ }^{56}$.

Pero la ausencia de gremios y reglamentos no explica por sí sola la proliferación de vendedores callejeros de libros en la ciudad de México a fines de la colonia. ¿Es posible que este fenómeno local respondiera a una coyuntura en el comercio atlántico del libro? En la década de 1760 -como ha mostrado Cristina Gómez- hubo un repunte en el tráfico autorizado de impresos, seguido de una nueva caída en la de $1770^{57}$. ¿Podemos suponer entonces que una oferta excesiva de libros fue lo que alentó la venta callejera? Es necesario, empero, formular preguntas adicionales sobre estos vendedores para poder determinar hasta qué punto su modesto trato se supeditó a los avatares de la Carrera de Indias, es decir, al gran negocio de la importación de libros en el mundo hispánico.

¿Quiénes eran esos individuos? ¿En qué se ocuparon antes de vender impresos en calles, portales y plazas? ¿Dónde se surtían o a través de quién? ¿Trabajaban para otros libreros? ¿Llegaron a establecer librerías? Las fuentes consultadas en el ramo Inquisición apenas permiten entrever el problema de la venta ambulante de impresos en la ciudad de México. La historiografía francesa ha impulsado novedosas investigaciones sobre el colportage en la época moderna, revelando la compleja dimensión sociocultural de esa modalidad de comercio y circulación.

Para ello fue imprescindible desechar la visión tradicional que confería a la venta y a los vendedores ambulantes un lugar exclusivamente marginal en el mundo del comercio librero. Por el contrario, nuevas fuentes mostraron que los vagabundos y mendigos eran en realidad excepciones, y que el colporta-

55 Thomas, 1984: 41-45.

56 Cabe aclarar que los ciegos de la Cofradía no eran mendigos ni vagabundos. Por el contrario, Jean-François Botrel mostró que eran individuos solventes, muchos de ellos casados y con hijos, y algunos incluso propietarios de inmuebles en la Corte. Todos habían pagado una cuota elevada para ingresar a un gremio que les garantizaba altos beneficios económicos gracias al monopolio que ejercían. Botrel, 1973.

57 Gómez Álvarez, 2011: 34. 
ge se constituía por redes de mercaderes migrantes que operaban en vastas zonas geográficas. No se niega la presencia de un colportage sauvage (rudimentario), alimentado por la «frustración social», amparado en los «espacios anónimos de la sociabilidad urbana» y la venta de ediciones prohibidas. Lo que se busca es mostrar la existencia paralela de un colportage basado en solidaridades familiares, lazos de paisanaje y redes mercantiles que rebasan los márgenes de las ciudades, organizado a partir de una boutique o «tienda matriz», apoyado en migraciones temporales (jóvenes comisionistas) y fuertemente jerarquizado ${ }^{58}$.

Ahora interesa atraer estas observaciones a los casos de tres vendedores de libros «a la mano». Los dos primeros están relacionados: Miguel y José Cueto. Poca duda cabe de fueron parientes, acaso hermanos ${ }^{59}$. En 1764 la Inquisición registró a Miguel bajo esa modalidad. Sin embargo, años atrás (1749) figuraba como «dueño» de un cajón de libros en el Portal de Mercaderes $^{60}$. En 1757 el tribunal lo registró como «tasador de libros», anotando que poseía un ejemplar del último Índice expurgatorio (1747), como dictaba la norma. Quizás un aprieto económico obligó a Cueto a dejar el cajón y retomar la venta ambulante. Más tarde se hizo administrador de la librería de la viuda de Cristóbal de Zúñiga -antes mencionada-, pero lo más significativo es que para 1768 era ya su propietario ${ }^{61}$. Fue común que los administradores o cajeros de tiendas se convirtieran en socios y andado el tiempo entraran en completa posesión del negocio (¿se casaría Cueto con la viuda de Cristóbal para la que siguió trabajando?). En este último año el Santo

58 Fontaine, 1996: 22-23. Fontaine analiza en concreto a los colporteurs libreros de los valles alpinos o montagnards. Por su parte, François Lopez, afirma que algunos de estos montañeses, tras haberse establecido en Cádiz, cruzaron el Atlántico hacia la América española, Lopez, 1984b.

59 Existe un tercer Cueto, llamado Manuel, quien se desempeñó asimismo como «administrador» de librerías y tasador de bibliotecas, pero al parecer nunca llegó a poseer su propia tienda. En 1741 administraba la librería de la calle de San Francisco y más tarde, en 1768, la que perteneció a Agustín de Espinosa, en la calle de la Monterilla. Véase el cuadro 1 en Moreno Gamboa, 2009b. Todavía en 1785 lo encontramos avaluando una biblioteca y declara ser vecino de la ciudad de México y «mercader de libros en ella», AGN, Inquisición, vol. 1252, exp. 5. Importa añadir que en 1742 Manuel Cueto aparece en los registros del navío El Luis José, como encargado de recoger en Veracruz (por ausencia del agente principal) cuatro cajas de libros y otros efectos, lo cual prueba que tenía contacto con mercaderes de la Carrera de Indias. Archivo General de Indias, Sevilla (AGI), Contratación, Registros de ida a Veracruz, leg. 1490 .

60 AGN, Indiferente Virreinal, caja 5983, exp. 4: «Pago de 300 pesos a cuenta de réditos a Miguel de Cueto dueño de un cajón de libros en el Portal de Mercaderes».

61 AGN, Inquisición, vol. 825, exp. 3. 
Oficio lo nombró «revisor y expurgador» de libros en reconocimiento a su pericia en la materia ${ }^{62}$. Con o sin tienda este personaje ejerció plenamente el oficio de librero. Conocía bien el negocio, estaba facultado para hacer avalúos de bibliotecas y librerías y redactar sus inventarios; sabía, en fin, qué autores y títulos estaban prohibidos y cuánto valían las ediciones en el mercado.

También José Cueto fue registrado como vendedor de libros «a la mano» en 1764. Pero unos años después se presentó ante la autoridad inquisitorial como «vecino de esta ciudad [de México] con cajoncillo» de libros en la Plaza Mayor (ver cuadro 1), donde continuaba en 1774. Este año la Audiencia le encomendó la tarea de levantar el inventario de la biblioteca del Colegio de San Gregorio. Osorio Romero apunta que su tarea fue más completa que la efectuada previamente por dos comisionados, pues Cueto incluyó el lugar y año de edición, y agrupó los libros por formatos ${ }^{63}$. Su designación como tasador de bibliotecas tan importantes como la de aquel ex colegio jesuita y su proceder en el registro de las obras muestran que era un librero experimentado, enterado del valor comercial de las ediciones.

A principios de julio de 1778 José pidió licencia a la Inquisición para vender los libros del difunto Manuel Cosuela, por encargo de su testamentaría. Cosuela era un «cargador» peninsular matriculado en el Consulado de Cádiz. Entre otras mercancías, gestionaba el traslado de Veracruz a la ciudad de México de cargamentos de libros recién llegados de la Metrópoli ${ }^{64}$. Sin duda ambos personajes se conocían de tiempo atrás y es posible que Cueto actuara en ocasiones como «agente» del mercader gaditano.

Los casos de Miguel y José Cueto enseñan que los libreros «a la mano» no eran necesariamente hombres ignorantes y marginados, como ha demostrado la historiografía francesa. También dejan ver que el comercio de impresos permitía cierto ascenso social y económico, pasar de la venta ambulante o semifija a la administración de una librería e incluso a su plena posesión. Además, entre los Cueto (incluido Manuel a quien cité a pie de página) el trato de libros se volvió un oficio familiar, situación singular en la librería novohispana y que habíamos pasado por alto.

Junto a personajes como los Cueto, calificados para redactar sendos inventarios, se hallaban no obstante vendedores incapacitados para firmar las notificaciones del Santo Oficio: Tomás de Haro y Francisco Rodríguez, por ejem-

\footnotetext{
62 Idem.

63 Romero, 1986: 79.

64 AGI, Contratación, Registros de ida a Veracruz, legs. 1484 al 1491.
} 
plo, no sabían escribir65. Puede resultar paradójico que estos intermediarios de la palabra impresa fueran analfabetas.

Otra cara de la venta ambulante de libros la proporciona el siguiente caso. A fines de 1799, un teniente de alcalde confiscó una estampa «con la expresión de la vista del Príncipe Carlos con el General Bonaparte acerca de los preliminares de la Paz» ${ }^{66}$. Se la entregó a la autoridad inquisitorial y luego, a solicitud de ésta, llevó al vendedor para que lo interrogaran. Se trataba de Ramón Alvino Muñoz, un «comerciante vendedor de libros a la mano». Tenía 47 años de edad, era «español», casado y originario de San Miguel el Grande. En la capital virreinal vivía en un «obragito» frente a la Casa del Real Apartado de Oro y Plata ${ }^{67}$, en el antiguo barrio de San Sebastián, al noreste de la catedral (ver mapa anexo al final) ${ }^{68}$. El barrio se ubicaba en los límites de la ciudad y estaba habitado por indios, castas y españoles pobres, como a todas luces lo era Muñoz.

Las estampas que iba vendiendo eran de factura local. Se las compró a un «abridor» o grabador de láminas de apellido Águila, quien vivía en Puente del Espíritu Santo (tres calles al oeste de la Plaza Mayor) ${ }^{69}$. Muñoz pagó nueve reales por la docena de estampas, pero vendió cada una «a real y medio y dos de ellas a dos reales». Su ganancia fue casi el doble de su corta inversión.

Respecto a la distribución de las estampas, se sabe que Muñoz acudió en primer lugar a los cajoneros del Parián: a Benito Cevallos le vendió una «para enviarla afuera» de la ciudad, otra a un cajero que no conocía, y una más a un gallego que vendía ropa en una «alacenita». Luego visitó el Real Palacio, donde un funcionario del Juzgado de Intestados le compró dos estampas. En la calle de la Monterilla vendió otra y dio una más «a su compañero» Juan

65 De Haro, se anotó: «no sabe firmar», AGN, Inquisición, vol. 1048, exp. 2, y de Rodríguez: «no sabe escribir», vol. 1172, exp. 14.

66 La estampa hacía referencia a los preliminares del tratado de paz de Loeben, celebrado en 1796 entre España y Austria; el «Príncipe Carlos» era el archiduque Carlos, heredero de la corona austriaca. Ver Carlos Mejía Chávez, "Napoleón de México: influencias, imaginarios y opiniones en torno al Gran Corso (1798-1824)", avance de investigación de tesis doctoral presentada en el Primer Seminario en El Colegio de México, junio 2016, cap. 1: 18.

67 AGN, Inquisición, vol. 1332, exp. 5.

68 Agradezco al licenciado Iván Alcántar su ayuda en la localización de la vivienda de Muñoz. Por otra parte, cabe explicar que durante el proceso de colonización San Sebastián Atzacoalco fue uno de los barrios indígenas que rodearon la traza española de la ciudad. Con el tiempo, estos barrios fueron ocupados cada vez más por españoles, perdiéndose la división original entre las dos «repúblicas». Hernández Franyuti, 2012: 73-74.

69 Muñoz aseguró que el propio Águila había grabado la lámina y que en el balcón de su vivienda tenía «puesto un rótulo de que allí se abren láminas», AGN, Inquisición, vol. 1332, exp. 5. 
José Urbiza, para que se la llevara a un sujeto «de Palacio». Es este un ejemplo de marginalidad en el mundillo del libro de la ciudad de México: un vendedor ambulante de un barrio pobre que distribuía impresos clandestinos ${ }^{70}$.

\section{CONSIDERACIONES FINALES}

En la segunda mitad del siglo XVIII las pequeñas librerías tuvieron cada vez mayor presencia en el comercio y la distribución de impresos en la ciudad de México. Las fuentes consultadas señalan también la existencia de distintos tipos de puestos semi-fijos y no pocos vendedores ambulantes. Este fenómeno se enmarca en un significativo aumento de las importaciones de libros en Nueva España, resultado del crecimiento demográfico y una relativa expansión de los lectores. Sin embargo, hacen falta más estudios sobre la oferta y las fuentes de abastecimiento de estos negocios para poder determinar hasta qué grado dependían directamente de redes mercantiles transoceánicas, o si se apoyaron sobre todo en la reventa local.

Los libreros medianos tendieron a ocupar locales en el mercado del Parián y el Portal de Mercaderes, puntos fundamentales de intercambio económico y social en la metrópoli novohispana. El «cajón de libros», un espacio comercial de dimensiones reducidas, fue quizá el establecimiento típico de la librería capitalina en el último siglo de la colonia. Siguiendo la ruta de otras mercancías suntuarias importadas (textiles y mercería principalmente), el libro entró de manera natural en ese tipo de tiendas.

Si bien en los cajones podían adquirirse costosos textos facultativos en latín y obras especializadas de gran formato, el examen de algunos inventarios apunta a que su principal función en el comercio urbano fue distribuir ediciones «populares» (religiosas, literarias y prácticas) e impresos viejos y usados, procedentes tanto de prensas europeas como novohispanas. De hecho, es en estos cajones donde probablemente arrancó en la ciudad de México un giro especializado: la «librería de viejo», que ya se menciona en los papeles inquisitoriales de principios del siglo XVIII. Queda por averiguar si la existencia de esta modalidad respondió a una práctica extendida entre los novohispanos, consistente en deshacerse de las bibliotecas particulares de sus familiares; o si a ello contribuyó la ausencia de herederos entre los propietarios de libros

70 No obstante que las estampas eran «de la clase de las prohibidas», los inquisidores decidieron devolvérselas a Muñiz porque «no nos parece correspondiente al decoro de este tribunal prohibir tales simplezas, que podría dar ocasión a murmuraciones o quejas de nuestros Aliados [los franceses]», AGN, Inquisición, vol. 1332, exp. 5. 
-nada extraño si se considera que muchos eran eclesiásticos y funcionarios recién llegados de España-. Aunado a esto, ¿cabría la posibilidad de un aumento del libro viejo en los cargamentos de los barcos?

Sin duda los dueños de los cajones de libros acudieron a las mismas fuentes de abastecimiento que los grandes libreros. Pero en virtud del tipo de ediciones que predominaba en sus inventarios, es factible que recurrieran más que nada a la compra de bibliotecas, a los remates públicos, a otros libreros de la ciudad y, por supuesto, a los impresores locales. A su vez, cabe la posibilidad de que los cajoneros colocaran algo de mercancía en los puestos de libros, haciendo las veces de intermediarios de los vendedores más modestos.

En cuanto a los «cajoncillos», alacenas y demás puestos semi-fijos, se vio que éstos se encontraban más o menos dispersos, pero dentro del área urbana que abarca el negocio librero y tipográfico de la capital de Nueva España (Plaza Mayor, portales y varias calles al suroeste), que era asimismo la del comercio de artículos suntuarios. Además de su volumen de venta - poco significativo si se compara con el de los almacenes y los cajones de libros-, otra diferencia importante entre los puestos y las tienda formales fueron las fuentes de aprovisionamiento y, por consiguiente, de crédito. De nuevo traigo a cuenta el caso de Sebastián Zumeta, quien surtía su mesilla en las librerías locales.

Aunque humilde, el comercio de los puesteros y los vendedores de libros «a la mano» permitía que el impreso circulara con mayor rapidez, llegando quizá a manos de individuos ajenos a los tradicionales grupos de lectores (clérigos y burócratas). Con todo, la venta callejera de libros era a todas luces una actividad inestable, como se desprende de las dos nóminas citadas, que en siete años se renovaron casi por completo. Además, sobre los ambulantes pesaba la sospecha y el disgusto de los funcionarios inquisitoriales porque evidenciaban su incapacidad para controlar una modalidad de comercio que parecía aumentar. Frente a la censura, los viandantes de libros tenían dos ventajas: la movilidad y una identidad difusa.

La librería «popular» y de segunda mano de la capital novohispana tuvo pues en los cajones, los puestos y la venta callejera tres importantes vías de distribución. Este tipo de comercio alentó la interacción entre las distintas categorías de tratantes, favoreció una incipiente especialización y permitió el ascenso económico y social de los tratantes de libros más experimentados. 
MAPA 1. UBICACIÓN DE CAJONES Y PUESTOS DE LIBROS EN LA CIUDAD DE MÉXICO (SEGUNDA MITAD DEL SIGLO XVIII) ${ }^{71}$

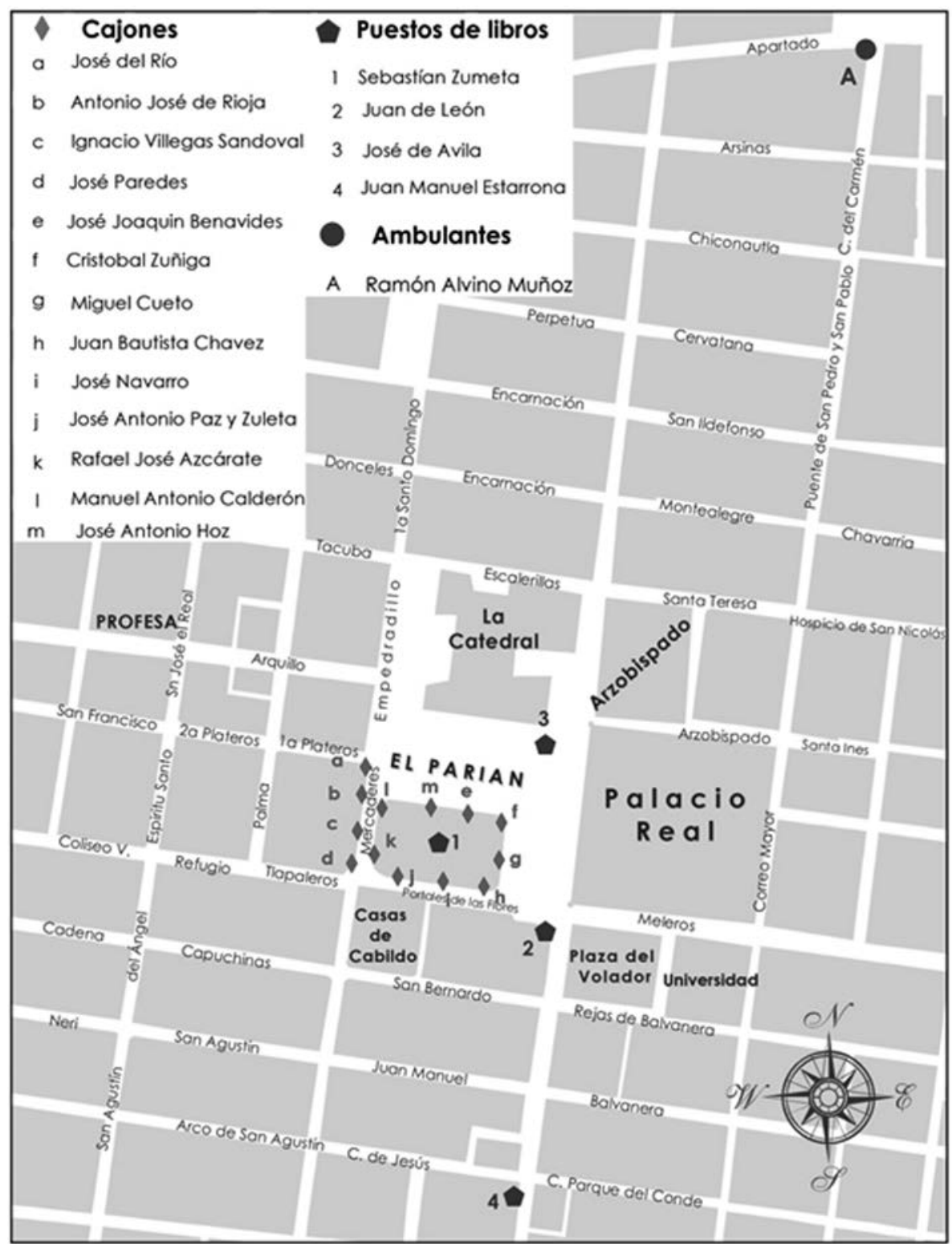

71 Agradezco a la maestra Laura Quiroz la elaboración de este mapa. 


\section{BIBLIOGRAFÍA}

Agulló y Cobo, Mercedes, La imprenta y el comercio de libros en Madrid (siglos XVI-XVIII), memoria para optar por el grado de doctor, Universidad Complutense de Madrid, Facultad de Geografía e Historia, 1992.

Botrel, Jean-François, "Les aveugles colporteurs d'imprimés en Espagne”, Mélanges de la Casa de Velázquez, 9 (Madrid, 1973): 417-483.

Botrel, Jean François, La difusión du livre en Espagne (1848-1914), Madrid, Bibliotheque de la Casa Velázquez, 1988.

Fontaine, Laurence, “Colporteurs de livres dans l'Europe du XVIIIe siècle”, Roger Chartier y Hans-Jürgen Lüsebrink (dirs.), Colportage et lecture populaire. Imprimés de large circulation en Europe XVIe-XIXe siècles, Paris, Institut Mémoires de l'Edition Contemporaine Maison des Sciences de L'Homme, 1996: 22-23.

García Cuadrado, Amparo, "La Compañía de Mercaderes de Libros de la Corte a mediados del siglo XVIII", Anales de Documentación, 4 (Murcia, 2001): 95-126.

Gómez Álvarez, Cristina, "Notas para el estudio de la circulación del libro usado en la Nueva España, 1750-1819”, J. Raúl Navarro García (coord.), Insurgencia y republicanismo, Madrid, CSIC, 2006: 11-25.

Gómez Álvarez, Cristina, Navegar con libros. El comercio de libros entre España y Nueva España (1750-1820), Madrid, Trama Editorial, UNAM, 2011.

González Cruz, Víctor Hugo, La distribución de las tiendas misceláneas y sus transacciones mercantiles. El comercio menudo de la ciudad de México, 1750-1803, tesis de licenciatura en Historia, Instituto Mora, México, 2013.

González González, Enrique y Gutiérrez Rodríguez, Víctor, “Libros en venta en el México de Sor Juana y de Sigüenza, 1655-1660", Carmen Castañeda (coord.), Del autor al lector I. Historia del libro en México, México D.F., Centro de Investigaciones y Estudios Superiores en Antropología Social, CONACYT, Miguel Ángel Porrúa, 2002: 103-132.

Guiot de la Garza, Lilia, "El competido mundo de la lectura: librerías y gabinetes de lectura en la ciudad de México, 1821-1855", Laura Suárez de la Torre (coord.), Constructores de un cambio cultural: impresores-editores y libreros en la ciudad de México, 1830-1855, México D.F., Instituto Mora, 2003: 437-510.

Gutiérrez Lorenzo, María del Pilar, “Arte de imprimir, negocio de impresor: costos de impresiones y salarios de operarios de la imprenta del Hospicio de Guadalajara, 1833-1839", Gutiérrez Lorenzo (coord.), Impresos y libros en la historia económica de México (siglos XVI-XIX), Guadalajara, Universidad de Guadalajara, 2007: 95-126.

Hernández Franyuti, Regina, "El análisis de la morfología urbana del antiguo barrio de San Juan a través de la cartografía antigua”, Marcela Dávalos (coord.), De 
márgenes, barrios y suburbios en la ciudad de México, siglos XVI-XXI, México, INAH, 2012: 67-84.

Lopez, François, "Gentes y oficios de la librería española a mediados del siglo XVIII”, Nueva Revista de Filología Hispánica, XXXIII (México D.F., 1984a): 165185 .

Lopez, François, "Un aperçu de la librairie espagnole au milieu du XVIIIe siècle", Arquivos do Centro cultural portugués, XX (París, 1984b): 469-494.

Medina, José Toribio, La imprenta en México, 1539-1821, vol. V, ed. facs., México D.F., UNAM, 1989.

Megged, Amos, “'Revalorando’ las luces en el mundo hispánico: la primera y única librería de Agustín Dhervé a mediados del siglo XVIII en la ciudad de México", Bulletin Hispanique, 111/1 (Bordeaux, 1999): 147-173.

Montiel Ontiveros, Ana Cecilia, "La librería de José Fernández de Jáuregui (17801800, ciudad de México)", Marina Garone Gravier, Isabel Galina y Laurette Godinas (eds.), Memorias del Congreso Internacional las Edades del Libro, Mexico, UNAM-IIB, 2012.

Montiel Ontiveros, Ana Cecilia, "Música en venta al doblar el siglo: el repertorio musical de la oficina de Jaúregui (1801)", Laura Suárez de la Torre (coord.), Los papeles para Euterpe. La música en la ciudad de México desde la historia cultural. Siglo XIX, México D.F., Instituto Dr. José María Luis Mora, 2015: 29-61.

Moreno Gamboa, Olivia, "Las obras científicas del inventario de la librería de Luis Mariano de Ibarra (1750)", Estudios de Historia Novohispana, 37 (México D.F., 2007): 169-196.

Moreno Gamboa, Olivia, La librería de Luis Mariano de Ibarra. Ciudad de México, 1730-1750, México D.F., Ediciones de Educación y Cultura, 2009a.

Moreno Gamboa, Olivia, "Hacia una tipología de los libreros de la ciudad de México (1700-1778)", Estudios de Historia Novohispana, 40 (México D.F., 2009b): 121-146.

Moreno Gamboa, Olivia, “Comercio y comerciantes de libros entre Cádiz y Veracruz en el tránsito hacia un nuevo orden (1702-1749)", Iván Escamilla, Matilde Souto y Guadalupe Pinzón (coords.), Resonancias imperiales. América y el Tratado de Utrecht de 1713, México, Instituto Mora, IIH-UNAM, 2015: 275-307.

Moreno Gamboa, Olivia, "Disonancias entre la Inquisición de México y la Suprema. A propósito de la censura del Ramillete de divinas flores (1690-1711)", Francisco Cervantes Bello y María del Pilar Martínez López-Cano (coords.), La dimensión imperial de la Iglesia novohispana, México, Instituto de Ciencias Sociales y Humanidades, Benemérita Universidad Autónoma de Puebla, Instituto de Investigaciones Históricas, UNAM, 2016: 165-198. 
Olvera Ramos, Jorge, Los mercados de la Plaza Mayor en la ciudad de México, México D.F., Ediciones Cal y Arena, Centro de Estudios Mexicanos y Centroamericanos, 2007.

Palmiste, Clara, "Los mercaderes de libros e impresos flamencos en Sevilla: organización de las redes mercantiles en Europa y América (1680-1750)", Ana Crespo Solana (coord.), Comunidades transnacionales: colonias de mercaderes extranjeros en el mundo atlántico (1500-1830), Madrid, Ediciones Doce Calles, 2010: 251-270.

Paredes Alonso, Javier, Mercaderes de libros. Cuatro siglos de historia de la Hermandad de San Gerónimo, Madrid, Fundación Germán Sánchez Ruipérez, 1989.

Ramírez Maya, María Carmina, "De barrio indígena a barrio obrero: Santa María Cuepopan en el Centro Histórico", Marcela Dávalos (coord.), De márgenes, barrios y suburbios en la ciudad de México, siglos XVI-XXI, México, INAH, 2012.

Ricard, Robert, "La plaza mayor en España y América Española (notas para un estudio)", Estudios geográficos, XI (Madrid, 1950): 321-327.

Romero, Osorio, Bibliotecas novohispanas, México D.F., SEP, Dirección General de Bibliotecas, 1986.

Rubial García, Antonio (coord.), La Iglesia en el México colonia, México D.F., BUAP, IIH-UNAM, Ediciones de Educación y Cultura, 2013.

Sánchez Espinosa, Gabriel, "Los puestos de libros de las gradas de San Felipe de Madrid en el siglo XVIII", Goya. Revista de arte, 335 (Madrid, 2011): 142-155.

Silva Riquer, Jorge, "La organización de las tiendas de pulpería en la ciudad de México, siglo XVIII", Manuel Miño y Sonia Pérez Toledo (coord.), La población de la Ciudad de México en 1790. Estructura social, alimentación y vivienda, México, UAM-Iztapalapa, Colmex, Conacyt, 2004.

Suárez Rivera, Manuel, “En el arco frontero al Palacio”. Análisis del inventario de la librería de Cristóbal de Zúniga y Ontiveros, 1758, tesis de Maestría en Historia, Facultad de Filosofía y Letras, UNAM, México, 2009.

Thomas, Diana M., The Royal Company of Printers and Booksellers of Spain: 17631794, New York, The Whitston Publishing Company, 1984.

Fecha de recepción: 24 de enero de 2015.

Fecha de aceptación: 12 de mayo de 2015. 


\section{The Enclosed World of the Book in the Capital of New Spain. Bookstores, Sale Posts and Street Vending (Eighteenth Century)}

The purpose of this work is to demonstrate the relevance of small bookstores in Mexico City's book trade. Unpublished first-hand sources enable us to show the success of these small businesses in the second half of the eighteenth century, and, at the same time, highlight the existence of a large group of street sellers dealing in printed works. Both phenomena belong to a period when the Atlantic book trade and typographic production in New Spain were growing. Similarly, the article also demonstrates the close relationship between bookstore status and their location in the city, bearing in mind that the main-square bookstalls and nearby street sellers stood out for selling "popular" editions, minor and second-hand works.

KeY WORDS: bookstores; bookstalls; street booksellers; Mexico City; New Spain, 18th Century. 